\title{
Effects of Radiofrequency Electromagnetic Fields and Ionizing Radiation on Amyloid Precursor Protein Processing and Cell Death
}

\author{
Kyeonghee Yoon $^{1} \cdot$ Sojung Choi ${ }^{1} \cdot$ Hyung-Do $\mathrm{Choi}^{2} \cdot \mathrm{Nam} \mathrm{Kim}^{3} \cdot$ Sang Bong Jeon ${ }^{2}$, \\ Kyung-Min Lim ${ }^{1} \cdot$ Hae-June Lee ${ }^{4, *} \cdot$ Yun-Sil Lee ${ }^{1, *}$
}

\begin{abstract}
The growing concerns regarding the adverse biological effects of radiofrequency electromagnetic fields (RF-EMFs), which are generated by common electronic devices, on the human brain led us to investigate their impact on Alzheimer's disease (AD). We aimed to establish the effects of RF-EMF on the expression of molecular markers associated with amyloid precursor protein (APP), cell death, and clonogenic survival in HT22 and APP-overexpressing 7w-PSML cells. We compared the effects of RF-EMF at a high specific absorption rate (SAR) level with the neuronal-cell-death-inducing effects of ionizing radiation (IR). RF-EMF exposure (8 W/kg SAR) promoted the protein expression of ADAM10 ( $\alpha$-secretase) in the HT22 cells $(p<0.05)$ and downregulated the APP mRNA level in the 7w-PSML cells $(p<0.01)$. In contrast, IR (10 Gy) significantly reduced the APP and a disintegrin and metalloproteinase 10 (ADAM10) levels without altering their respective mRNA levels in these cells. Interestingly, IR exposure significantly upregulated BACE1 ( $\beta$-secretase) at both the protein and mRNA levels, suggesting adverse effects in AD. IR induced cell death and reduced clonogenic survival in both cell lines. Although RF-EMF (high SAR level) influenced APP processing, it did not induce any deleterious change in either cell line. Thus, further studies are necessary to clarify the influence of RF-EMF on AD.
\end{abstract}

Key Words: Amyloid Protein Precursor Processing, Cell Death, Ionizing Radiation, RF-EMF.

\section{INTRODUCTION}

Alzheimer's disease $(\mathrm{AD})$ is an irreversible, progressive neurodegenerative brain disorder that slowly deteriorates memory and causes cognitive impairment. Although the cause of $\mathrm{AD}$ is not fully understood, several hypotheses have been proposed.
The amyloid hypothesis is the most commonly accepted model, according to which the accumulation of amyloid $\beta(\beta A)$ in the brain is one of the pathological markers of $\mathrm{AD}[1,2]$. The amyloid hypothesis, that the accumulation and deposition of oligomeric or fibrillar $\beta A$ peptide is the primary cause of $A D$, has been the mainstream concept underlying $\mathrm{AD}$ research for over

Manuscript received June 14, 2020 ; Revised September 6, 2020 ; Accepted September 15, 2020. (ID No. 20200614-084J)

${ }^{1}$ Graduate School of Pharmaceutical Sciences, Ewha Womans University, Seoul, Korea.

${ }^{2}$ Department of EMF Research Team, Electronics and Telecommunications Research Institute, Daejeon, Korea.

${ }^{3}$ School of Electrical and Computer Engineering, Chungbuk National University, Cheongju, Korea.

${ }^{4}$ Division of Basic Radiation Bioscience, Korea Institute of Radiological \& Medical Sciences, Seoul, Korea.

*Corresponding Author: Hae-June Lee (hjlee@kirams.re.kr) and Yun-Sil Lee (yslee0425@ewha.ac.kr)

This is an Open-Access article distributed under the terms of the Creative Commons Attribution Non-Commercial License (http://creativecommons.org/licenses/by-nc/4.0) which permits unrestricted non-commercial use, distribution, and reproduction in any medium, provided the original work is properly cited.

(c) Copyright The Korean Institute of Electromagnetic Engineering and Science. All Rights Reserved. 
20 years [3-6]. In the normal condition, $\beta A$ is cleaved from amyloid precursor protein (APP) by $\beta$ - and $\gamma$-secretase and released from the cell, where it is rapidly degraded or removed. However, in $\mathrm{AD}$ patients, the abnormally increased $\beta \mathrm{A}$ induces $\beta A$ amyloid fibril formation and accumulation in the brain, leading to neuronal cell death and neurodegeneration [3].

$\beta A$ processing involves two pathways: the non-amyloidogenic pathway and the amyloidogenic pathway [7]. APP synthesized de novo in the endoplasmic reticulum is the basis for both pathways [8]. In the non-amyloidogenic pathway, $\alpha$-secretases start a series of chemical reactions. ADAM10 is an $\alpha$-secretase enzyme that belongs to the family of a disintegrin and metalloproteinase (ADAM). ADAM10 cleaves APP to generate sAPP $\alpha$ and P83. Then P83 is cleaved by $\gamma$-secretase into P3 and the APP intracellular domain $[1,9]$. In contrast, in the amyloidogenic pathway, APP is first cleaved by $\beta$-secretase (BACE1) to produce sAPP $\beta$ and $C 99$. This pathway also releases the neurotoxic $A \beta$ peptide, which forms oligomers that further aggregate into amyloid plaque deposits [8], which are found in the brains of $\mathrm{AD}$ patients. The abnormal accumulation of $\mathrm{A} \beta$ occurs in the early stages of the pathological phase, and this eventually leads to $\mathrm{AD}[10]$. The correlation between memory deficits and amyloid plaque deposits in $\mathrm{AD}$ transgenic mice models supports this hypothesis. Compared to other hypotheses, the amyloid hypothesis remains the best-defined and most widely accepted theory on the pathogenesis of $\mathrm{AD}$ [2].

Neurodegenerative diseases and the cognitive functions of the brain may be influenced by radiofrequency electromagnetic fields (RF-EMFs), to which we are continuously exposed. With the rapid increase in the use of mobile phones, the adverse effects of these radiations have been recognized as a matter of public concern. Many studies have been carried out to discern whether RF-EMF exposure affects the cognitive functions of the brain. The results have revealed that RF-EMF exposure can lead to positive beneficial effects [11-15], negative harmful effects [16, 17], or no effects [1, 18-20]. In $\mathrm{AD}$ transgenic animal models, positive beneficial effects after long-term RF-EMF exposure were usually observed [11-14]. Although the RFEMF exposure was for a relatively short period of time (2 months), beneficial effects were observed in models with severe $\mathrm{AD}$, such as $5 \mathrm{xFAD}$ and old APPsw mice models [14]. On the contrary, following exposure to RF-EMF, harmful effects were observed in non- $\mathrm{AD}$ transgenic mouse models, such as $\mathrm{C} 57-$ $\mathrm{BL} / 6$ or CD- $1[16,17]$. In the case of in vitro experimentation, there have been very few studies on neurodegenerative diseases such as $\mathrm{AD}$. In one study, possible therapeutic beneficial effects were observed on $\beta A$-induced oxidative stress when primarycultured rat astrocytes were exposed to RF-EMFs for 24 hours [15]. However, some studies have also shown no changes in the neuronal cells after RF-EMF exposure [1, 21].
Cognitive impairment is a major side effect of the brain's exposure to ionizing radiation (IR) [22]. It has been reported that a single dose of $10 \mathrm{~Gy}$ can cause memory impairment in animal models $[23,24]$. Exposure to radiation may also lead to the loss of neural precursor cells and to impeded hippocampal neurogenesis [25, 26]. Moreover, the brain's exposure to IR has been reported to promote the development of $\mathrm{AD}$ [27]. A case control study of brain radiotherapy suggested an increased risk of developing $\mathrm{AD}$ and radiotherapy (RT)-related cognitive defects after whole-brain irradiation [28]. Although cognitive impairment has been observed in humans and animals following brain irradiation, the underlying mechanisms leading to brain dysfunction remain largely unknown.

In this study, we performed in vitro experiments to elucidate whether long-term-evolution (LTE) RF-EMF or IR affect the expression of molecular markers of APP processing, cell death, and clonogenic survival in HT22 or the APP-overexpressing $7 \mathrm{w}$-PSML cells. The $7 \mathrm{w}$-PSML is a stably transfected Chinese hamster ovary (CHO)-based cell line that expresses both the wild-type human APP and mutant presenilin-1 (M146L), and is an efficient model for the detection of APP [29]. Because the endogenous expression of APP in the neuronal cells is usually very low, it poses a technical barrier to studying APP processing and its mechanism [1]. Thus, $7 \mathrm{w}$-PSML has been used as a cellular model system for studying APP processing in AD in vitro.

\section{MATERIALS AND METHODS}

\section{Radio Frequency Exposure System}

The radial transmission line (RTL) exposure system [30-32] was used as an in vitro exposure system because it can simultaneously expose large numbers of culture flasks. The LTE signal (1.76 GHz) [33] was applied to the RTL exposure system (Fig. 1(a)). The exposure level and schedule were controlled by a control unit, and the maximum input power was $60 \mathrm{~W}$. The input signal was fed through a conical antenna. The conical antennas typically have broadband characteristics, and the return loss of the exposure system with an antenna was under $-10 \mathrm{~dB}$ from $800 \mathrm{MHz}$ to $5 \mathrm{GHz}$. The external dimensions of the exposure system were $843 \mathrm{~mm}, 825 \mathrm{~mm}$, and $315 \mathrm{~mm}$ (Fig. 1(b)). The exposure system was specifically designed for controlling the environmental conditions, including the ventilation, humidity, and temperature. To maintain the $\mathrm{CO}_{2}$ density and humidity inside the chamber, the gas from an incubator was circulated throughout the chamber. Additionally, a water pump that circulated water throughout the bottom of the cavity was used to control the temperature; the pump was used to protect the culture medium from temperature rises during the exposure by circulating water throughout the cooling system. The SAR 


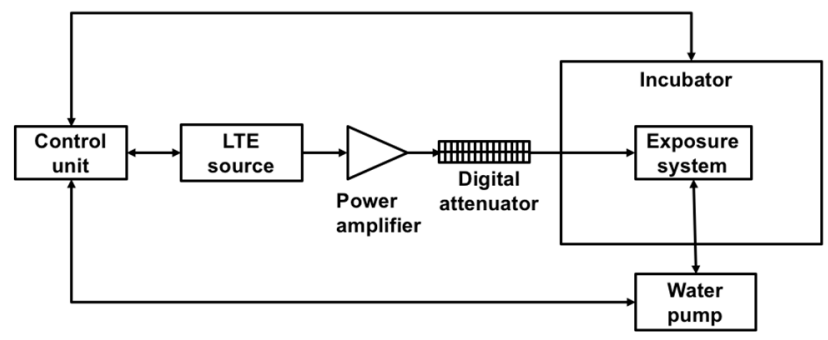

(a)

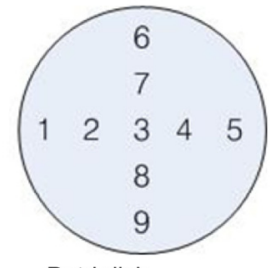

Petri dish

Conical antenna

(c)

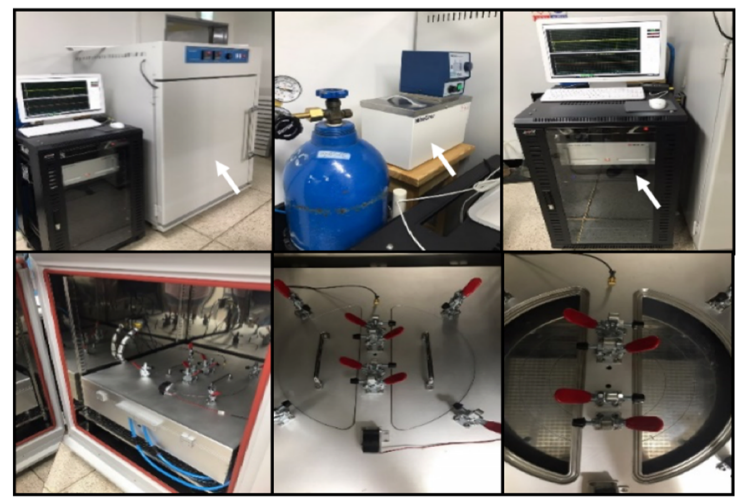

(e)

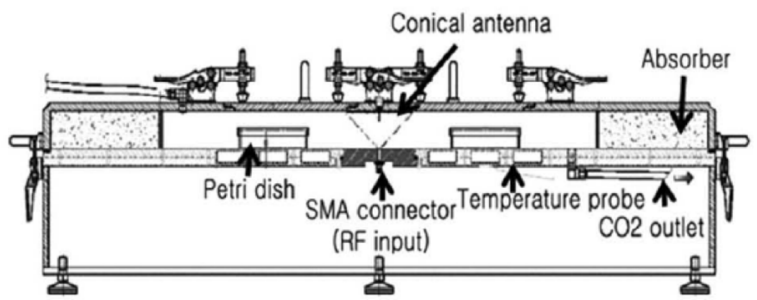

(b)

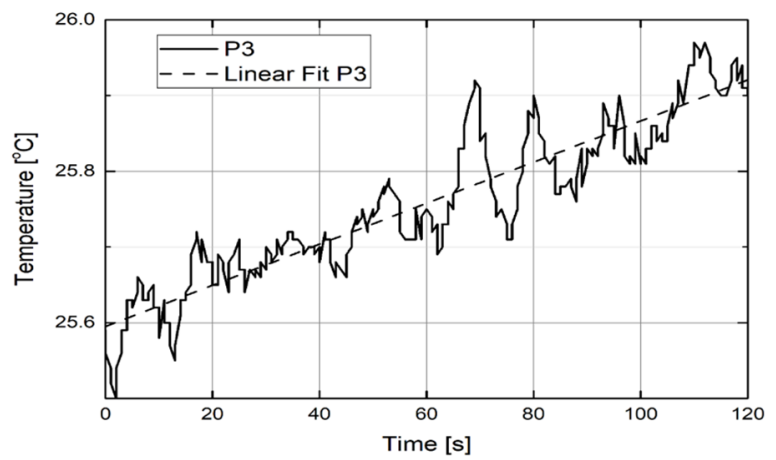

(d)

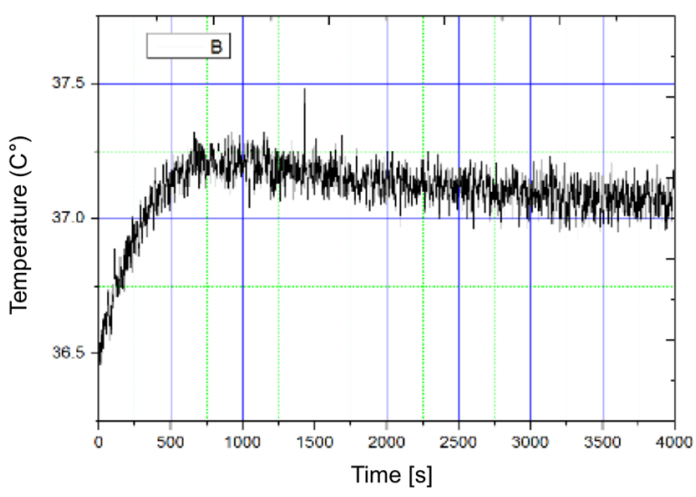

(f)

Fig. 1. RF radiation exposure system for the in vitro study. (a) Block diagram of RTL exposure. (b) Cross-sectional view of the RTL exposure chamber. (c) Measurement points in the culture plate. (d) Temperature and linear fitting for the center point at the LTE 1.76 $\mathrm{GHz}$ frequency. The temperature was measured without circulating water during RF exposure. (e) External pictures of the exposure system: $\mathrm{CO}_{2}$ incubator, water pump, power supplier with computer (arrows, upper panels), and ferrite shielding system inside a $\mathrm{CO}_{2}$ incubator (lower panels). (f) Maintenance of temperature in the exposure location during the exposure period.

measurement was performed using a Luxtron 812 fiber-optic thermometer (Luxtron Corp., Santa Clara, CA, USA) with a thermal resolution of $0.1^{\circ} \mathrm{C}$. For the measurement, the probes were located at nine points inside a petri dish (Fig. 1(c)). Fig. 1 (d) shows the graphs of the temperature of the cell culture at the center of the inside of a petri dish for LTE $1.76 \mathrm{GHz}$. The SAR values were calculated from the temperature rise using Eq. (1).

$$
\mathrm{SAR}=C_{p} \frac{\Delta T}{\Delta t} \approx C_{p} \frac{d T}{d t},
$$

where $C_{p}, T$, and $t$ are the specific heat $\left(\mathrm{J} / \mathrm{kg} \cdot{ }^{\circ} \mathrm{C}\right)$, temperature rise by exposure $\left({ }^{\circ} \mathrm{C}\right)$, and exposure time $(\mathrm{s})$, respectively. Three measurements were carried out at nine points, as shown in Fig. 1(d). The mean value and standard deviation of the SAR measurements in the entire sample were $0.155 \pm 0.004 \mathrm{~W} / \mathrm{kg}$, which were normalized to the input power at the feeding point. Pictures of the exposure system are shown in Fig. 1(e). No significant rise in temperature was noted as a result of the cooling system during RF-EMF exposure (Fig. 1(f)).

\section{Radiation Exposure}

The cells in the $60 \mathrm{~mm}$ and $100 \mathrm{~mm}$ petri dishes were exposed to radiation (0-10 Gy as a single dose) generated by a ${ }^{137} \mathrm{Cs}$ gamma ray source (Elan 3000; Atomic Energy of Canada, Mississauga, Canada) at a dose rate of $3.81 \mathrm{~Gy} / \mathrm{min}$. The radiation workers received annual radiation safety management train- 
ing from the Korea Foundation of Nuclear Safety (KoFONS).

\section{Cell Culture}

HT22 is an immortalized mouse hippocampal cell line. These cells have been used as established in vitro cellular models for $\mathrm{AD}$, and have functional cholinergic properties related to the cognitive defects of AD. The $7 \mathrm{w}$-PSML cells were provided by Dr. Inhee Mook (Seoul National University College of Medicine, Seoul, Korea). The $7 \mathrm{w}$-PSML is a CHO cell line that is stably transfected with both wild-type human APP and mutant presenilin-1 (M146L); thus, it is an effective model for the detection of APP and its own metabolites [30]. This cell line was grown in high-glucose Dulbecco's Modified Eagle Medium (DMEM) containing 10\% fetal bovine serum and 1\% penicillin-streptomycin solution $(100 \times)$. The exponentially growing cells were maintained at $37^{\circ} \mathrm{C}$ in an incubator with a humidified atmosphere of $95 \%$ air and $5 \% \mathrm{CO}_{2}$. HT22 cells were utilized to establish an HSP25-overexpressing cell model; transfection of the stable cell line was carried out using Lipofectamine 2000 (Invitrogen). HSP25 was cloned into p3xFLAG-Myc-CMV containing an $\mathrm{N}$-terminal Flag tag. After transfection, the cells were incubated for 24 hours. Next, geneticin disulfate (G418) was used to select the transfected cells. HT22 stable cells expressing HSP25 were cultured under the same conditions as with the HT22 control cells.

\section{Cell Viability Assay}

Cell viability against EMF exposure (SAR $8 \mathrm{~W} / \mathrm{kg}$ ) and $\gamma-$ ray irradiation was determined using 3-(4,5-dimethylthiazol-2yl)-2,5-diphenyltetrazolium bromide (MTT) assay (Amersham Pharmacia Biotech, Buckinghamshire, UK). Briefly, the cells were seeded at a $1 \times 10^{4}$ cells/well density in 96-well plates and exposed to RF-EMF or $\gamma$-rays. After 24-hour incubation, the optical-density readings were recorded.

\section{Flow Cytometry Analysis}

The cells were washed once with phosphate-buffered saline (PBS), dissociated using Trypsin-EDTA, and centrifuged for 3 minutes at $1,300 \mathrm{rpm}$ and $4^{\circ} \mathrm{C}$. The pellet was washed with 1 $\mathrm{mL}$ of PBS. Then PBS and $1 \mu \mathrm{g} / \mathrm{mL}$ propidium iodide $(1 \mathrm{~mL}$ each) were added to each polystyrene round-bottom tube. Finally, flow cytometric analysis was performed using a FACScan flow cytometer (BD Bioscience, Franklin Lakes, NJ, USA).

\section{Quantitative Real-Time Polymerase Chain Reaction ( $q R T$ - PCR)}

Total RNA was extracted using QIAzol (QIAGEN). The RNA purity and concentration were measured with a NanoDrop (ND-2000; Thermo Scientific, Waltham, MA, USA), and cDNA was synthesized using the ReverTra Ace RT-PCR kit (Toyobo Co. Ltd., Osaka, Japan). PCR was performed to assess the expression of the candidate genes using primers designed for SYBR Green-based detection (BIO92020; Bioline Inc., Memphis, TN, USA). The APP, BACE1, ADAM10, and $\beta$-actin (internal control gene) were measured via $\mathrm{qRT}-\mathrm{PCR}$ using the sequences provided in Table 1.

\section{Cycloheximide (CHX) Chase Assay}

HT22 and $7 \mathrm{w}$-PSML cells were seeded $\left(4 \times 10^{5}\right.$ cells $)$ and treated with 20 or $40 \mu \mathrm{g} / \mathrm{mL} \mathrm{CHX,} \mathrm{respectively.} \mathrm{Following}$ CHX treatment, the cells were exposed to 5 or $10 \mathrm{~Gy} \mathrm{IR.}$

\section{Western Blotting}

Cells were lysed with immune precipitation buffer, and the protein concentration of each sample was determined through the Bradford method (Bio-Rad, Hercules, CA, USA). The samples were boiled for 5 minutes, and an equal amount of protein was analyzed with sodium dodecyl sulfate and polyacrylamide gel (6\%-15\%) under the standard conditions. The horseradish peroxidase activity was measured using enhanced chemiluminescence (EzWestLumi, Tokyo, Japan). The protein band intensity was visualized using ChemiDoc (Bio-Rad) and was quantified using ImageJ Software 1.45 (National Institutes of Health, Bethesda, MD, USA).

\section{Colony-Forming Assay (CFA)}

The colonies of HT22 or 7w-PSML cells that survived were

Table 1. Primer sequences for qRT-PCR

\begin{tabular}{lllc}
\hline & & \multicolumn{1}{c}{ Sequence (5'-3') } & Species \\
\hline APP & Forward & 5'-CATCTTCACTGGCACACCGT-3' & Human/mouse \\
& Reverse & 5'-CAAACTCTACCCCTCGGAAC-3' & \\
\hline ADAM10 & Forward & 5'-AATTCTGCTCCTCTCCTGGGC-3' & Human/mouse \\
& Reverse & 5'-CCTCTTCATTCGTAGGTTGA-3' & Human/mouse \\
\hline \multirow{2}{*}{ BACE1 } & Forward & 5'-TGTGGAGATGGTGGACAACCTG-3' & \\
& Reverse & 5'-TGCCTCTGGTAGTAGCGATG-3' & Human/mouse \\
\hline$\beta$-actin & Forward & 5'-CGCCACCAGTTCGCCATGGA-3' & \\
& Reverse & 5'-TACAGCCCGGGGAGCATCGT-3' & \\
\hline
\end{tabular}


determined after 9 days of IR or RF-EMF exposure. The cells were fixed by adding a fixation solution (methanol:acetate $=7: 3$, RT for 10 minutes), and the colonies were stained by adding $500 \mathrm{~mL}$ PBS containing $0.4 \%$ trypan blue. The colonies consisting of $>50$ cells were counted using a Fluorchem SP counter (Alpha Innotech, San Leandro, CA, USA). Each assay was performed in triplicate.

\section{Antibodies}

The following antibodies were used in this study: anti-APP (A8717; Sigma-Aldrich, St. Louis, MO, USA), purified- $\beta$ A antibody (BioLegend Cat\# 803001), APP/ $\beta A$ antibody (2450S; Cell Signaling Technology, Danvers, MA, USA), BACE1 antibody (sc33711; Santa Cruz Biotechnology, Dallas, TX, USA), ADAM10 antibody (ab1997; Abcam, Cambridge, UK), cleaved caspase-3 antibody (9661S, Cell Signaling Technology), cleaved PARP1 (9451S, Cell Signaling Technology), and $\beta$ actin antibody (sc47778, Santa Cruz Biotechnology).

\section{Statistics}

Values are displayed as mean \pm SEM (standard error of the mean). Student $t$-test was used for comparing two groups, and one-way ANOVA was applied for experiments with more than three subgroups, using the GraphPad Prism program (version 8.0; GraphPad Software, San Diego, CA, USA). The results were considered statistically significant when the $p$-values were less than 0.05 .

\section{RESULTS}

\section{Effects of RF-EMF and IR on the Molecular Markers of APP Processing}

First, we compared the APP levels of the HT22 and $7 \mathrm{w}^{-}$ PSML cells using Western blotting and confirmed that APP was stably overexpressed in the 7w-PSML cells (Fig. 2(a)). Next, we quantified the mRNA levels of APP, BACE1, and ADAM10 (which are involved in APP processing) in the HT22 and $7 \mathrm{w}$-PSML cells using qRT-PCR. As expected, the $7 \mathrm{w}^{-}$ PSML cells showed higher mRNA levels of APP and BACE1, major factors contributing to $A \beta$ production. However, the $7 w^{-}$ PSML cells also exhibited a high mRNA level of ADAM10 (Fig. 2(b)).

The expression levels of the APP processing proteins, APP, BACE1, ADAM10, and $\beta A$ in the HT22 and 7w-PSML cells were examined 24 hours after their exposure to RF-EMF (8 $\mathrm{W} / \mathrm{kg}$ SAR). In the case of the $7 \mathrm{w}$-PSML cells, $\beta$ A could not be detected. The level of ADAM10 was increased by RF-EMF in the HT22 cells compared to that in the non-exposed cells. The $7 \mathrm{w}$-PSML cells, on the other hand, exhibited slightly decreased APP levels following RF-EMF exposure, but the decrease was not statistically significant. The levels of BACE1 and ADAM10 were not altered in the 7w-PSML cells (Fig. 3(a)). To determine whether exposure to RF-EMF affects the mRNA levels, HT22 and 7w-PSML cells were harvested at 24 hours after RF-EMF exposure, and qRT-PCR was performed. In contrast with the Western blotting results, the mRNA levels of APP, BACE1, and ADAM10 were not altered by RF-EMF exposure in the HT22 cells. Interestingly, downregulated APP mRNA was observed in the $7 \mathrm{w}$-PSML cells due to RF-EMF (Fig. 3(b)). These data suggest that RF-EMF may influence APP processing in both the HT22 and $7 \mathrm{w}$-PSML cells, although their effects may not be sufficiently associated with $\beta \mathrm{A}$ alteration.

To clarify the effect of IR on APP processing in the neuronal cells, the levels of APP, BACE1, ADAM10, and A $\beta$ were measured in both the HT22 and 7w-PSML cells 24 and 48 hours after exposure to 10 Gy IR. The APP expression was decreased by IR in both cell lines, and these effects were more profound at 48 hours than at 24 hours. Notably, the expression level of BACE1 in the HT22 cells was significantly increased at 24 and 48 hours after IR exposure. As for the $7 \mathrm{w}-\mathrm{PSML}$ cells, the BACE1 expression was increased only at 48 hours. Only the expression level of ADAM10 at 48 hours was decreased by IR in both the HT22 and 7w-PSML cells. In the case of the amy-

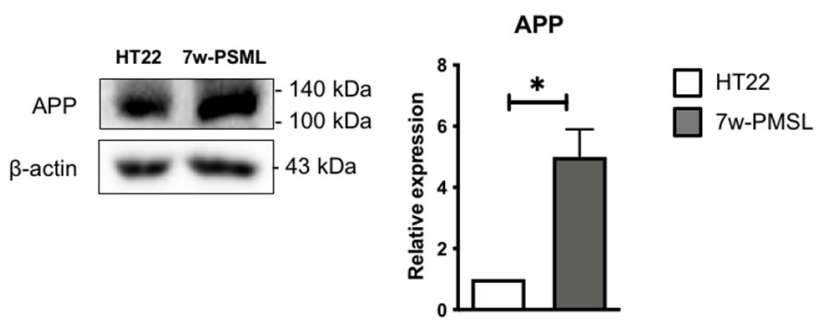

(a)
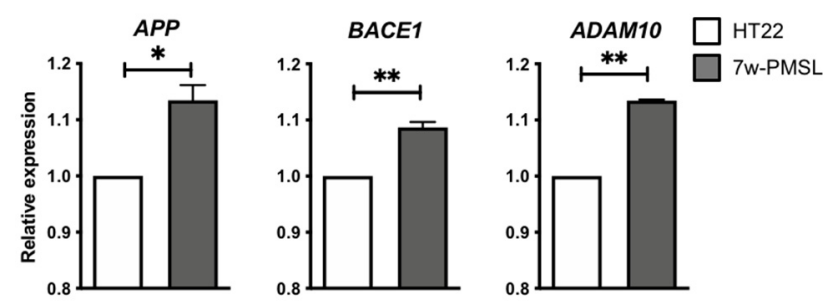

(b)

Fig. 2. Expression of the basal levels of molecular markers for APP processing in the HT22 and 7w-PSML cells. (a) Representative photo of the Western blots for APP; $\beta$-actin was used as a loading control. (b) qRT-PCR analysis of the APP, BACE1, and ADAM10 mRNAs. The data are expressed as foldwise increases of the levels in the HT22 cells $\left({ }^{*} p<0.05\right.$ and ${ }^{* *} p<0.01$ compared to the HT22 cells, $\mathrm{n}=3$, mean $\pm \mathrm{SEM}$ ). 


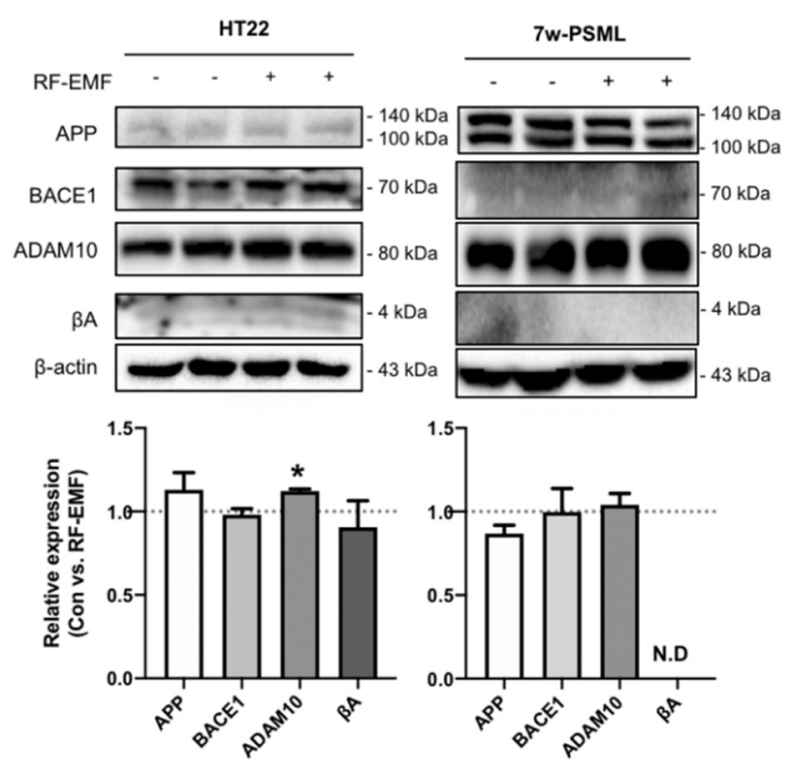

(a)

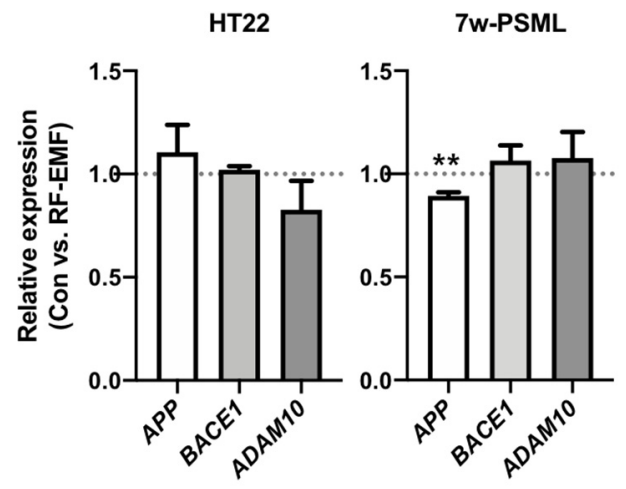

(b)

Fig. 3. Expression variations of molecular markers for APP processing in the HT22 and 7w-PSML cells due to RF-EMF. The HT22 and $7 \mathrm{w}$-PSML cells $\left(5 \times 10^{5}\right.$ cells $)$ were seeded and irradiated with RF-EMF (8 W/kg) for 24 hours. The cells were harvested, and (a) Western blotting and (b) qRTPCR were performed. The qRT-PCR data were expressed as foldwise increases of the unexposed control, and $\beta$-actin was used as the loading control. The relative band density of Western blotting was also analyzed $\left({ }^{*} p<0.05\right.$ and ${ }^{* *} p<0.01$ compared to the corresponding unexposed control cells, mean \pm SEM, $\mathrm{n}=3$ ).

loidogenic APP processing product, $\beta$ A could hardly be detected, but the expression levels were decreased 24 and 48 hours after IR in the HT22 cells, which may be due to the decreased expression of APP. Similar to RF-EMF exposure, $\beta$ A expression in the $7 \mathrm{w}$-PSML cells could not be detected at all (Fig. 4(a)). To elucidate whether the altered expression of APPprocessing proteins by IR was regulated at the transcriptional level, qRT-PCR analysis was performed. The HT22 and 7wPSML cells were irradiated with 10 Gy IR to assess the mRNA expressions of APP, BACE1, and ADAM10 24 hours after irradiation. Only the mRNA expression of BACE1 was significantly increased by IR exposure in both the HT22 and 7wPSML cells (Fig. 4(b)). Interestingly, IR influenced the APP levels, but not the mRNA levels. Further, the APP stability was examined using CHX treatment. In both the HT22 and $7 \mathrm{w}^{-}$ PSML cells, the expression level of APP decreased proportionally with the time after CHX treatment. Moreover, IR decreased the APP stability in both the HT22 and 7w-PSML cells (Fig. 4(c)).

\section{Effect of RF-EMF and IR on Cell Death and Clonogenic Survival}

In this study, we applied LTE exposure with a relatively high SAR $(8 \mathrm{~W} / \mathrm{kg})$ compared to the permissible limit $1.4 \mathrm{~W} / \mathrm{kg}$ SAR for local exposure allowed by the International Commission on Non-Ionizing Radiation Protection (ICNIRP) guideline. We aimed to investigate the effects of RF-EMF on cell death or clonogenic survival in the HT22 and 7w-PSML cells 24 hours after exposure to $8 \mathrm{~W} / \mathrm{kg}$ SAR RF-EMF. Apoptotic markers, such as cleaved PARP1 and cleaved caspase-3, were detected via Western blotting, but RF-EMF exposure did not affect them in either the HT22 or 7w-PSML cells (Fig. 5(a)). Next, experiments were performed to measure the extent of cell death or growth inhibition resulting from RF-EMF exposure using flow cytometry, MTT assay, and CFA. No significant differences were observed between the RF-EMF-exposed cells and the non-exposed controls in either cell line (Fig. 5(b)-(d)). To determine the effect of IR on cell death, the cleaved PARP1 and caspase- 3 were quantified at 24 hours after IR exposure. The expressions of cleaved PARP1 and caspase- 3 were increased after exposure to 10 Gy IR in both the HT22 and $7 \mathrm{w}-$ PSML cells (Fig. 6(a)). The evaluation of cell death or growth inhibition through flow cytometry and MTT assay showed that the IR-induced cell death significantly increased and the cell proliferation of both cell lines was inhibited (Fig. 6(b) and (c), respectively). The clonogenic survival data also revealed that the colony number of the HT22 cells was significantly decreased by IR in a dose-dependent manner $(p<0.01)$. The colonies of the $7 \mathrm{w}$-PSML cells were also decreased by IR in a dose-dependent manner $(p<0.01)$. Notably, there was no statistical difference in the colony-forming ability against IR between the HT22 and 7 wPSML cells $(p=0.23$, analyzed via two-way ANOVA) (Fig. $6(d))$.

It was previously reported that HSP25 (or HSP27 for humans) protected neuronal cells from IR-induced cell damage [34]. This drove us to examine whether HSP25 overexpression protected HT22 cells from IR-induced cell death. Notably, IR exposure reduced the cleaved PARP1 and caspase-3 expressions when HSP25 was overexpressed (Fig. 7(a)). Moreover, HSP25 overexpression increased the APP level (Fig. 7(b)), 

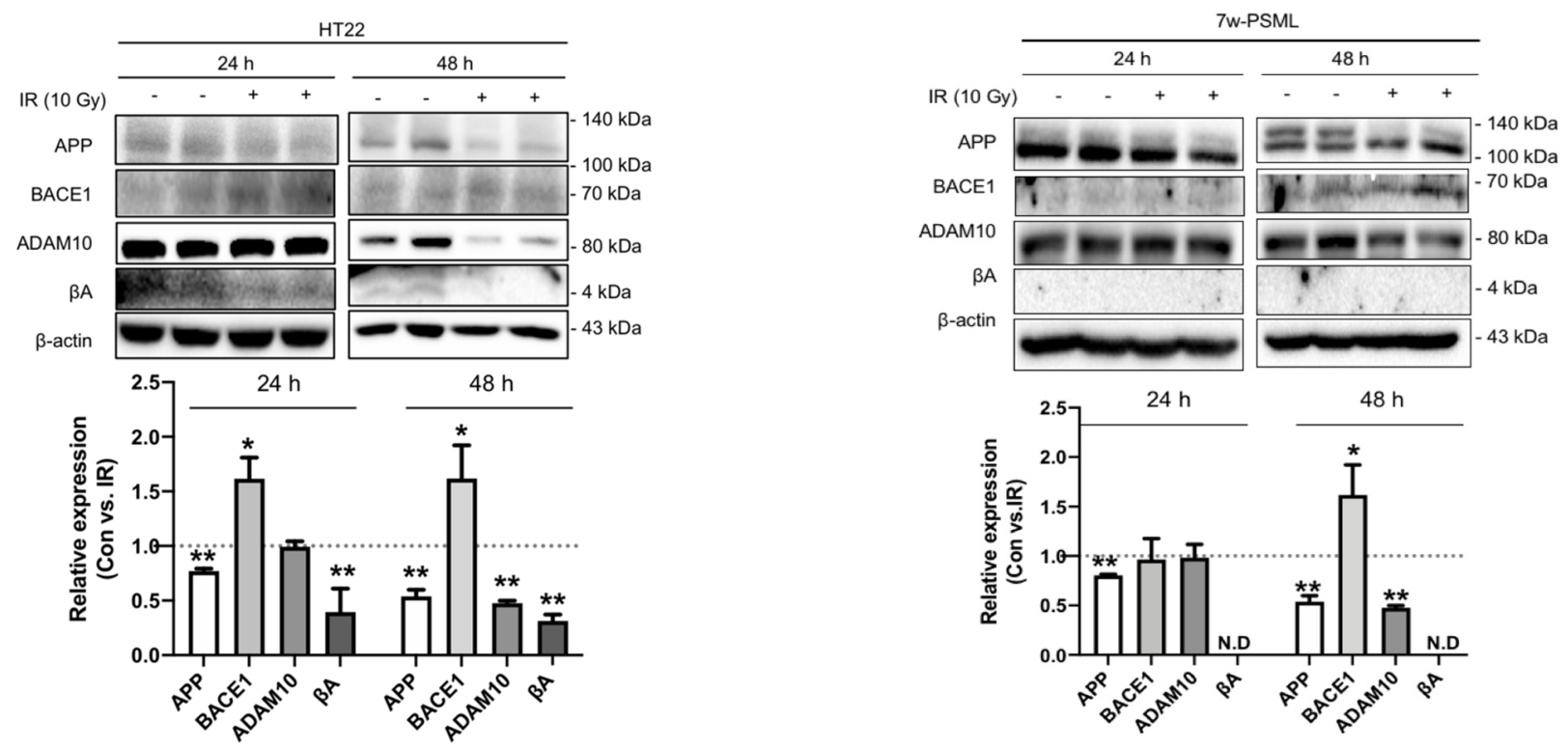

(a)

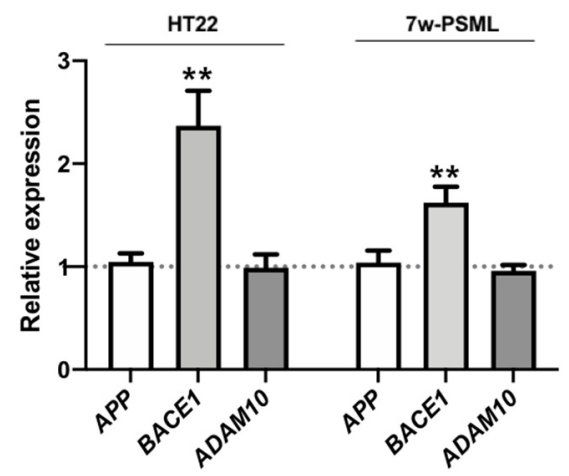

(b)

HT22

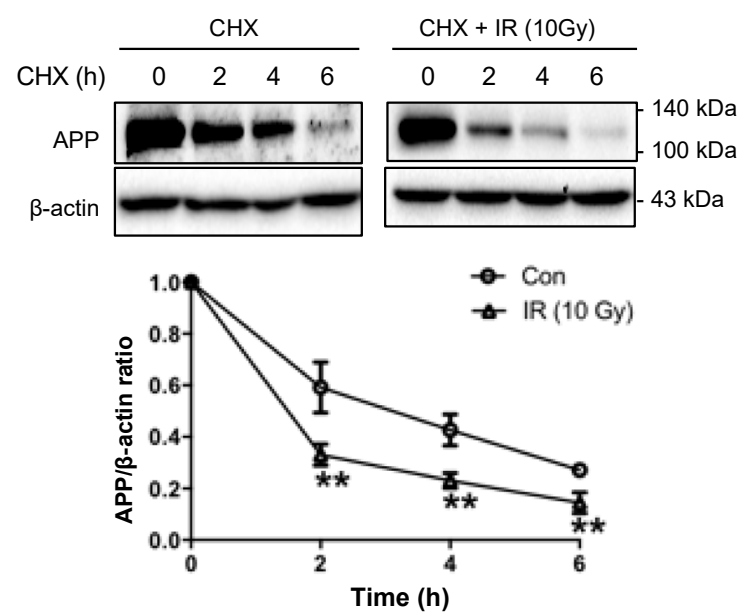

7w-PSML

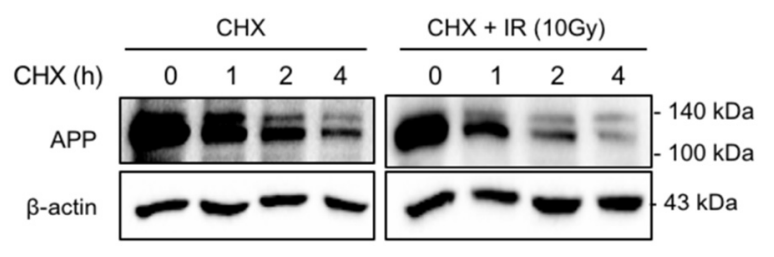

$\rightarrow$ Con

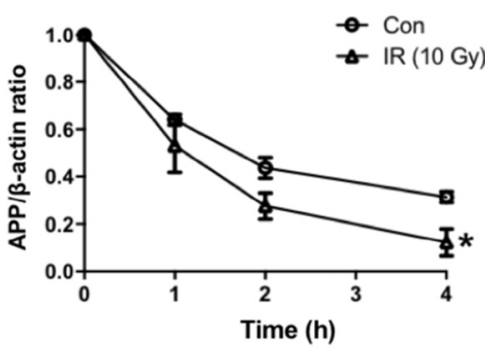

(c)

Fig. 4. Expression of molecular markers for APP processing by IR in the HT22 and 7w-PSML cells. The HT22 and 7w-PSML cells were seeded $\left(3 \times 10^{5}\right.$ cells $)$ and exposed to $10 \mathrm{~Gy}$ IR. After 24 or 48 hours, the cells were harvested, and cell lysates were used to perform (a) Western blotting and (b) qRT-PCR. The qRT-PCR data were expressed as foldwise increases of the non-irradiated control, and $\beta$-actin was used as the loading control. (c) HT22 and 7w-PSML cells were treated with CHX at $40 \mu \mathrm{g} / \mathrm{mL}$ and $20 \mu \mathrm{g} / \mathrm{mL}$, respectively, with or without $10 \mathrm{~Gy}$ IR. At the indicated time points, the cells were harvested, and Western blotting was performed. $\beta$ actin was used as the loading control. The relative band density of Western blotting was also analyzed $\left({ }^{*} p<0.05\right.$ and ${ }^{* * *} p<0.01$ compared to the corresponding non-irradiated cells, mean \pm SEM). 


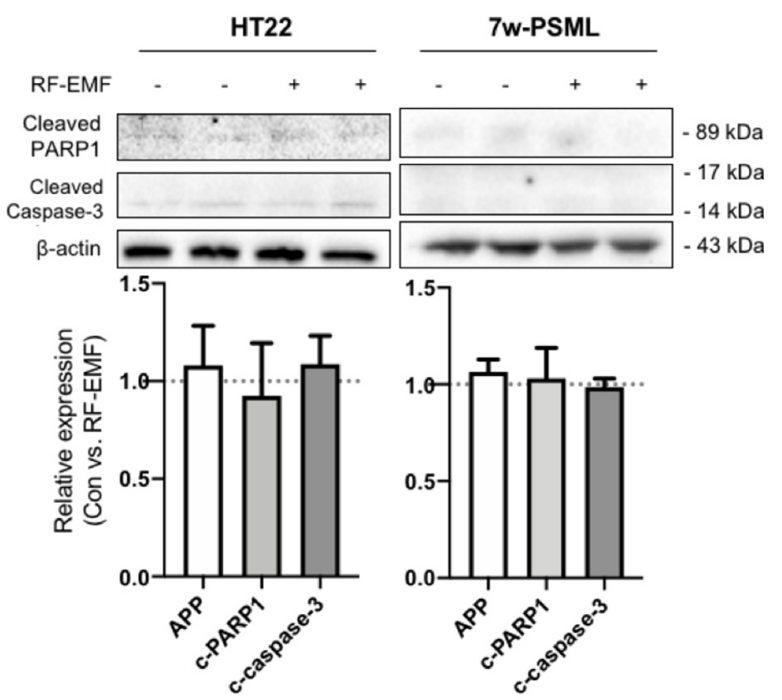

(a)

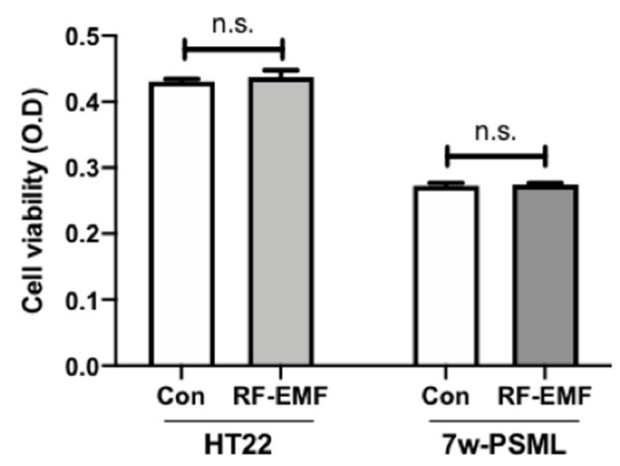

(c)

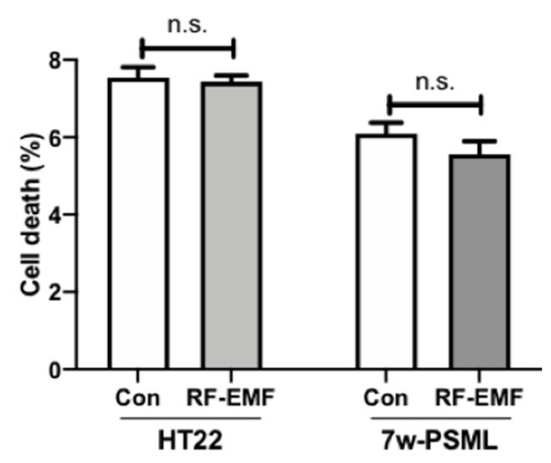

(b)

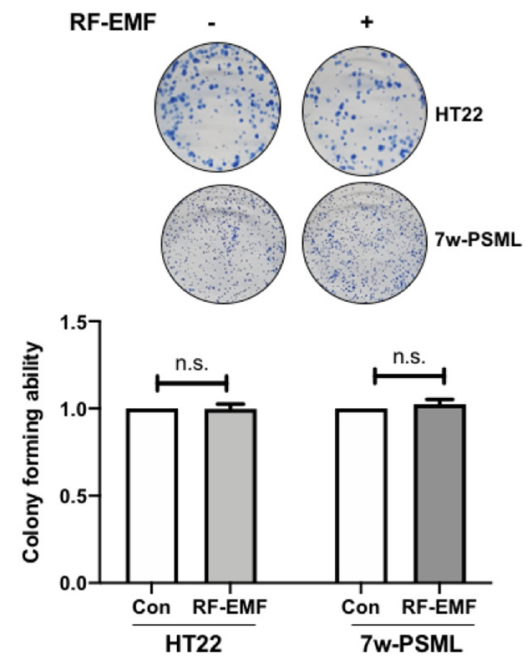

(d)

Fig. 5. Effects of RF-EMF on cell death. HT22 and 7w-PSML cells were seeded $\left(5 \times 10^{5}\right.$ cells $)$ and then exposed to RF-EMF $(8 \mathrm{~W} / \mathrm{kg})$ for 24 hours. (a) The cells were harvested, and Western blotting was performed for cleaved PARP1 and cleaved caspase-3; $\beta$-actin was used as the loading control. The relative expressions compared to those in the non-exposed control were quantified $(n=3)$. (b) The cell death and (c) the cell viability were analyzed using flow cytometry $(n=5)$ and MTT assay $(n=5)$, respectively. (d) Colony-forming assay (CFA) was performed for the HT22 and 7w-PSML cells, which were seeded at $1 \times 10^{3}$ cells/well. The cells were then exposed to RF-EMF ( $8 \mathrm{~W} / \mathrm{kg}$ ) for 24 hours and were incubated for another 9 days prior to CFA $(n=3)$. The data are represented as mean \pm SEM. n.s. $=$ no significance.

which was mediated by the increased stability of APP (Fig. 7(c)). These results suggest that IR-induced cell injury can modulate the APP levels and their stability.

\section{DISCUSSION}

To investigate how RF-EMF affects neurodegenerative diseases such as $\mathrm{AD}$, we compared the effects of RF-EMF and IR on APP processing using in vitro AD models. In this study, we exposed the cells to $8 \mathrm{~W} / \mathrm{kg}$ SAR, which is over fivefold higher than the permissible limit (1.4 W/kg SAR) according to the ICNIRP local-exposure guidelines. However, we did not detect any induction of cell death or inhibition of clonogenic survival. Lee et al. [21] also simultaneously exposed HT22 cells to two types of RF-EMF to evaluate their effects on cell death and beta amyloid treatment ( $4 \mathrm{~W} / \mathrm{kg}$ SAR level; CDMA $2 \mathrm{~W} / \mathrm{kg}+$ WCDMA $2 \mathrm{~W} / \mathrm{kg}$ for 2 hours). Similarly, no effects were observed on cell proliferation, cell cycle distribution, and cell death as a result of RF-EMF in the absence or presence of $A \beta$ treatment in the cells. Moreover, we found that RF-EMF induced 


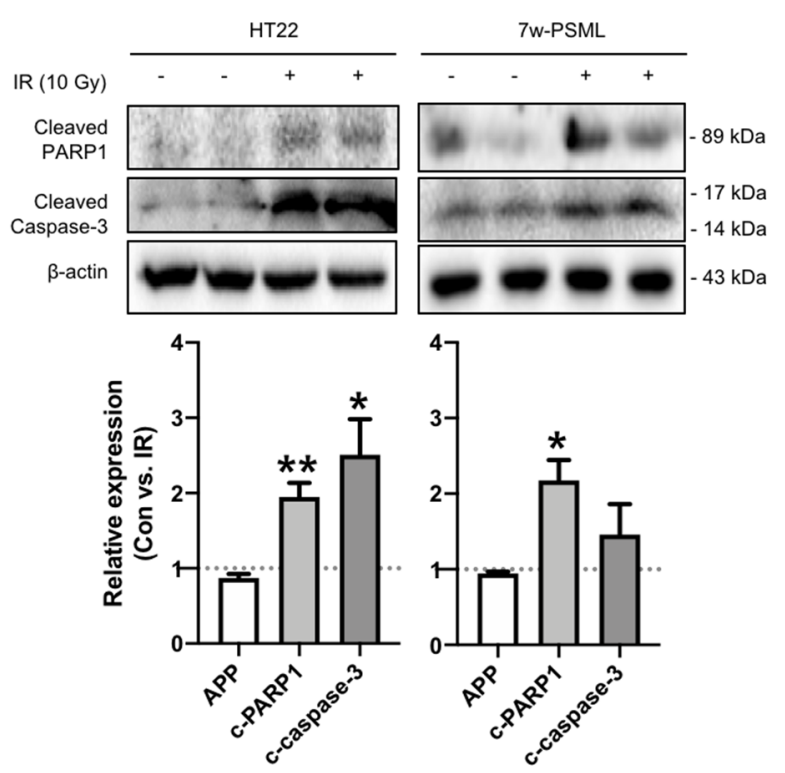

(a)

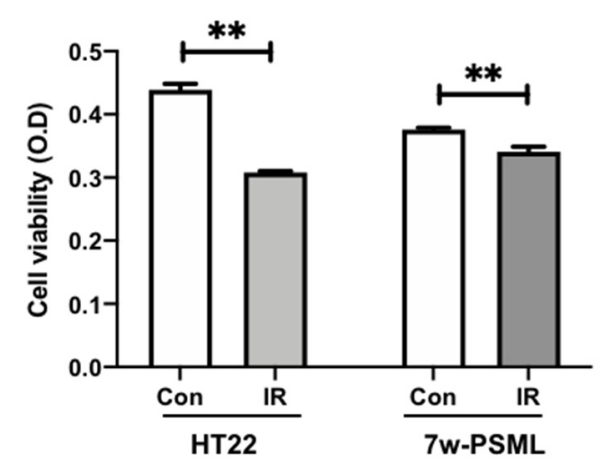

(c)

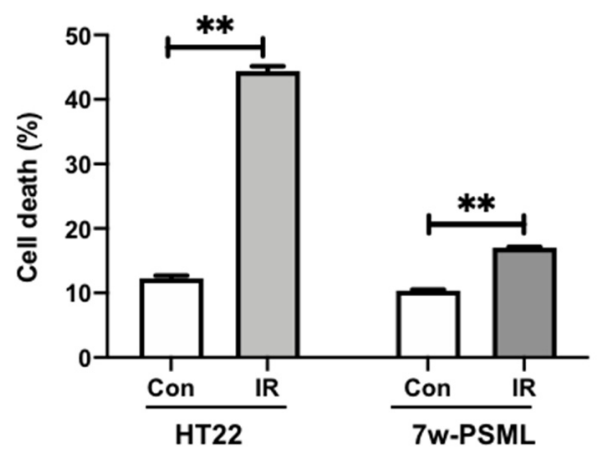

(b)

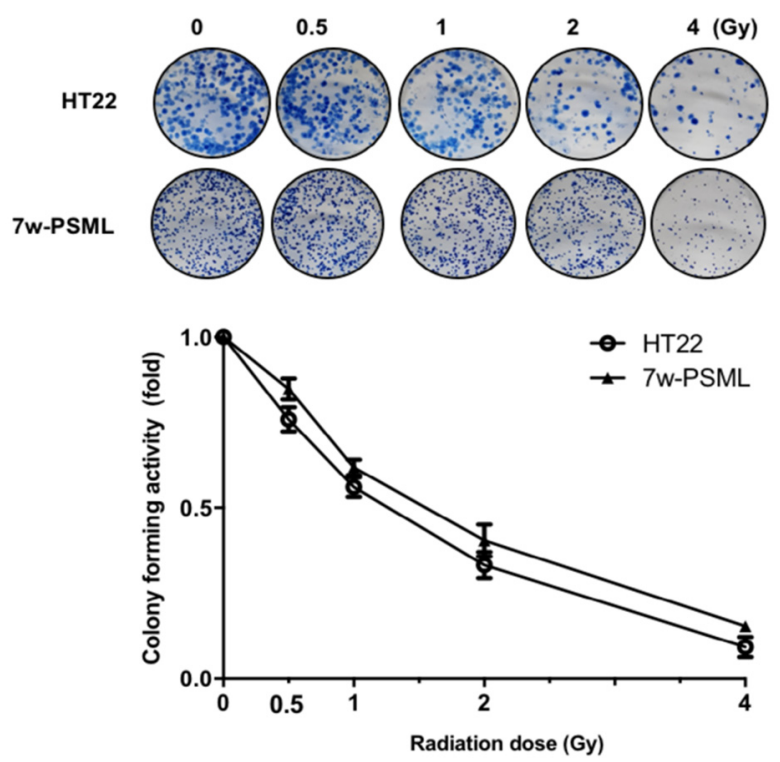

(d)

Fig. 6. Effects of IR on cell death. HT22 and 7w-PSML cells were seeded ( $5 \times 10^{5}$ cells) and exposed to 10 Gy IR for 24 hours. The cells were harvested, and (a) Western blotting, (b) flow cytometry analysis, and (c) MTT assay were performed on them. The relative band density of Western blotting was also analyzed and compared to that of the respective non-irradiated controls; $\beta$-actin was used as the loading control. (d) Colony-forming assay (CFA) was performed after seeding HT22 and 7w-PSML cells at a density of $1 \times$ $10^{3}$ cells/well and exposing them to IR at the indicated doses. After 9 days of IR exposure, CFA analysis was performed. The graph shows the related foldwise decreases compared to each non-exposed control. Each experiment was conducted in triplicate $\left(^{*} p<0.05\right.$ and ${ }^{* *} p<0.01$ compared to the corresponding non-irradiated cells, mean $\left.\pm \mathrm{SEM}\right)$.

the upregulation of ADAM10 in the HT22 cells, a significant downregulation of APP at the transcriptional level, and a slight decrease in the APP level in the APP-overexpressing $7 \mathrm{w}^{-}$ PSML cells. These results suggest that RF-EMF may provide some beneficial effects on APP processing; however, we were not able to directly observe changes in $\beta$ A. These results are consistent with those of our previous study, which showed the positive effects of RF-EMF, such as a reduction of APP and $\beta \mathrm{A}$ deposition in the brain and improvement in the behavioral disorders of 5xFAD mice after long-term WCDMA RF-EMF exposure (over 8 months) [11]. However, in contrast to our results, Park et al. [1] reported that the RF-EMF (WCDMA, 6 W/kg SAR, 2 hours per day for 3 days) exposure of the HT22 and $7 \mathrm{w}$-PSML cell lines did not induce any change related to APP-processing proteins. Unlike Park et al. [1], we applied higher electromagnetic exposure levels and a longer exposure 

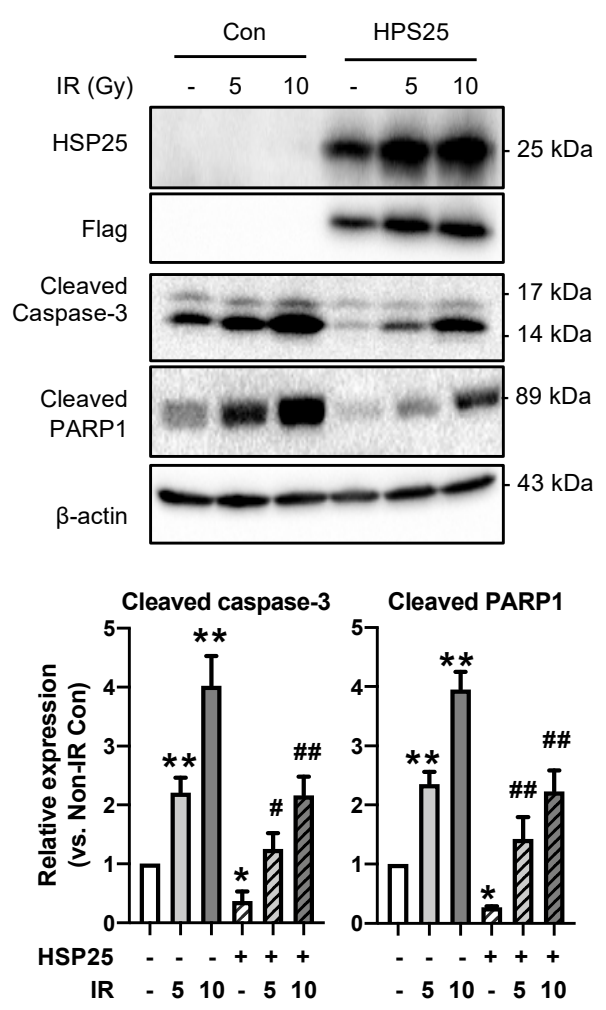

(a)

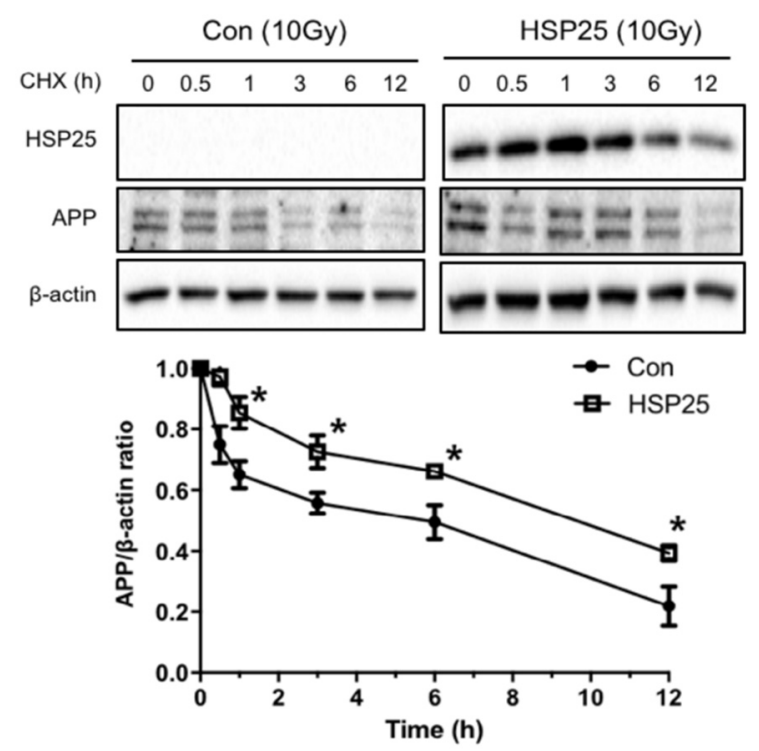

(c)

time to the cells and found some significant changes in APP processing. Further studies are thus needed to investigate whether various experimental conditions, including extended exposure time (over 24 hours) and/or higher SAR levels, at more than $8 \mathrm{~W} / \mathrm{kg}$ RF-EMF affect APP processing.

Interestingly, in our experiment, IR significantly upregulated BACE1 at both the transcriptional and protein levels. However, $\beta A$ was not increased despite the decrease in the APP levels of both the HT22 and 7w-PSML cells. Instead, the $\beta A$ expression was decreased due to the decreased APP level. IR may affect the
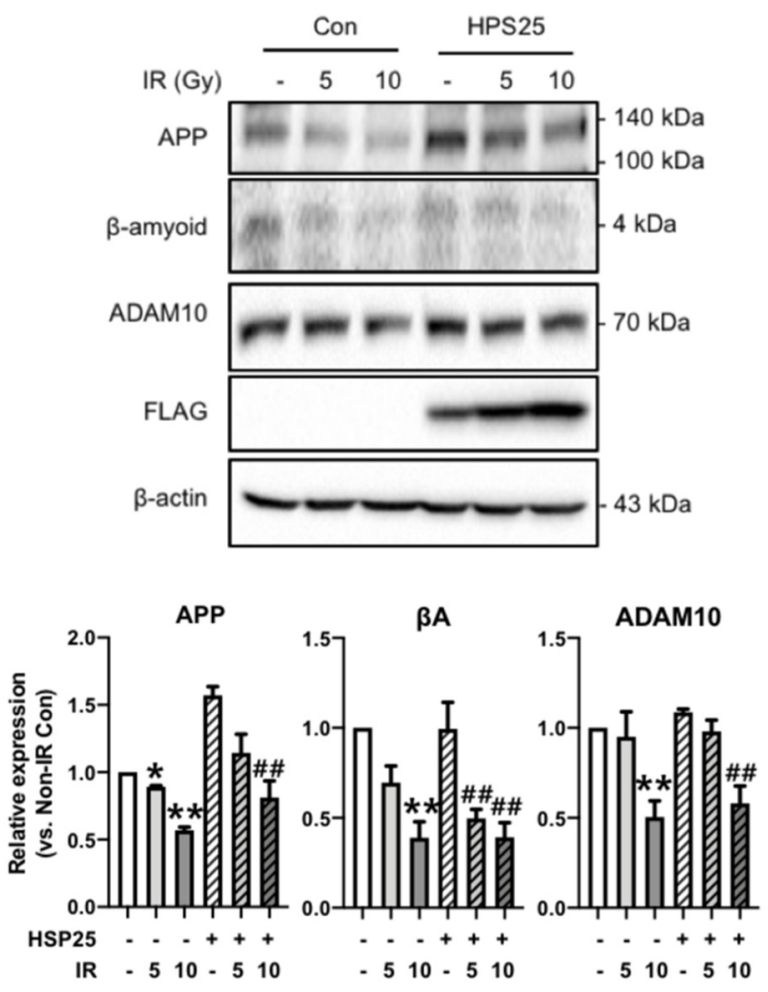

(b)

Fig. 7. HSP25 overexpression protects cells from IR and stabilizes APP. Control and Flag-tagged HSP25-overexpressing HT22 cells were seeded $\left(8 \times 10^{5}\right.$ cells). (a) Cell death markers were detected using Western blotting 48 hours after IR (5 and $10 \mathrm{~Gy}$ ). (b) The expression of molecular markers for APP processing after IR was detected using Western blotting in the control HT22 and HSP25overexpressing HT22 cells. The graph shows the results obtained by measuring the density of the band determined by Western blotting. (c) Cells were seeded at $2 \times 10^{5}$ and treated with CHX $(100 \mu \mathrm{g} / \mathrm{mL})$. At the indicated time points, the cells were harvested, and cell lysates were used to perform Western blotting; $\beta$-actin was used as the loading control. ${ }^{*} p<0.05$ and ${ }^{* *} p<0.01$ vs. the corresponding unexposed control HT22 cells; ${ }^{\#} p<0.05$ and ${ }^{\# \#} p<0.01$ vs. the corresponding unexposed HSP25-overexpressing HT22 cells, mean $\pm \mathrm{SEM}, \mathrm{n}=3$.

APP processing signaling cascade by influencing the APP stability. Moreover, HSP25, which was reported to inhibit IRinduced brain damage [35], reduced the IR-mediated damages such as cell death indicated by cleaved PARP1 and cleaved caspase-3, and regulated the stability of APP. This finding is notable and implies that RT may have adverse effects on the brain of $\mathrm{AD}$ patients; however, the IR dose was too high to effectively investigate its effect on only APP processing without compromising or evaluating the survival of the cells. Therefore, further studies should be conducted at lower IR doses that will 
not affect the cell fate. Additionally, more detailed experiments are needed to elucidate the APP stability during IR exposure in the context of HSP25 expression.

\section{CONCLUSION}

Our study demonstrated that RF-EMFs altered APP processing, one of the main pathways in the pathogenesis of $\mathrm{AD}$. RF-EMFs affected the level of ADAM10 and the transcription level of APP without any effect on cell death or clonogenic survival. These results suggest the potential of RF-EMFs to influence the pathogenesis of $\mathrm{AD}$. Therefore, our finding can be used as evidence of the biological effect of RF-EMFs. Further studies should be conducted to clarify the effects of RF-EMF on $\mathrm{AD}$ using various cell organelles.

This work was supported by the ICT R\&D program of MSIT/IITP (No. 2017-0-00961, Study on the EMF Exposure Control in Smart Society; No. 2019-0-00102, A Study on Public Health and Safety in a Complex EMF Environment). We thank Professor Inhee Mook-Jung for providing the $7 \mathrm{w}$-PSML cell line.

\section{REFERENCES}

[1] J. Park, J. H. Kwon, N. Kim, and K. Song, "Effects of 1,950 $\mathrm{MHz}$ radiofrequency electromagnetic fields on Abeta processing in human neuroblastoma and mouse hippocampal neuronal cells," Journal of Radiation Research, vol. 59, no. 1, pp. 18-26, 2018.

[2] S. H. Omar, C. J. Scott, A. S. Hamlin, and H. K. Obied, "The protective role of plant biophenols in mechanisms of Alzheimer's disease," Journal of Nutritional Biochemistry, vol. 47, pp. 1-20, 2017.

[3] F. Kametani and M. Hasegawa, "Reconsideration of amyloid hypothesis and tau hypothesis in Alzheimer's disease," Frontiers in Neuroscience, vol. 12, article no. 25, 2018.

[4] J. Hardy and D. Allsop, "Amyloid deposition as the central event in the aetiology of Alzheimer's disease," Trends in Pharmacological Sciences, vol. 12, no. 10, pp. 383-388, 1991.

[5] D. J. Selkoe, "The molecular pathology of Alzheimer's disease," Neuron, vol. 6, no. 4, pp. 487-498, 1991.

[6] J. A. Hardy and G. A. Higgins, "Alzheimer's disease: the amyloid cascade hypothesis," Science, vol. 256, no. 5054, pp. 184-185, 1992.

[7] L. F. Hernandez-Zimbron and S. Rivas-Arancibia, "Deciphering an interplay of proteins associated with amyloid beta 1-42 peptide and molecular mechanisms of Alzheimer's disease," Reviews in the Neurosciences, vol. 25, no. 6, pp. 773-
783, 2014.

[8] S. Jiang, Y. Li, X. Zhang, G. Bu, H. Xu, and Y. W. Zhang, "Trafficking regulation of proteins in Alzheimer's disease," Molecular Neurodegeneration, vol. 9, article no. 6, 2014.

[9] H. Zheng and E. H. Koo, "Biology and pathophysiology of the amyloid precursor protein," Molecular Neurodegeneration, vol. 6, article no. 27, 2011.

[10] A. Serrano-Pozo, M. P. Frosch, E. Masliah, and B. T. Hyman, "Neuropathological alterations in Alzheimer disease," Cold Spring Harbor Perspectives in Medicine, vol. 1, no. 1, article no. a006189, 2011.

[11] Y. J. Jeong, G. Y. Kang, J. H. Kwon, H. D. Choi, J. K. Pack, N. Kim, Y. S. Lee, and H. J. Lee, "1,950 MHz electromagnetic fields ameliorate $A \beta$ pathology in Alzheimer's disease mice," Current Alzheimer Research, vol. 12, no. 5, pp. 481492, 2015.

[12] Y. Son, J. S. Kim, Y. J. Jeong, Y. K. Jeong, J. H. Kwon, H. D. Choi, J. K. Pack, N. Kim, Y. S. Lee, and H. J. Lee, "Longterm RF exposure on behavior and cerebral glucose metabolism in 5xFAD mice," Neuroscience Letters, vol. 666, pp. 64-69, 2018.

[13] S. Banaceur, S. Banasr, M. Sakly, and H. Abdelmelek, "Whole body exposure to $2.4 \mathrm{GHz}$ WIFI signals: effects on cognitive impairment in adult triple transgenic mouse models of Alzheimer's disease (3xTg-AD)," Behavioural Brain Research, vol. 240, pp. 197-201, 2013.

[14] G. W. Arendash, T. Mori, M. Dorsey, R. Gonzalez, N. Tajiri, and C. Borlongan, "Electromagnetic treatment to old Alzheimer's mice reverses $\beta$-amyloid deposition, modifies cerebral blood flow, and provides selected cognitive benefit," PLoS One, vol. 7, no. 4, article no. e35751, 2012.

[15] A. Tsoy, T. Saliev, E. Abzhanova, A. Turgambayeva, A. Kaiyrlykyzy, M. Akishev, S. Saparbayev, B. Umbayev, and S. Askarova, "The effects of mobile phone radiofrequency electromagnetic fields on $\beta$-amyloid-induced oxidative stress in human and rat primary astrocytes," Neuroscience, vol. 408, pp. 46-57, 2019.

[16] M. P. Ntzouni, A. Skouroliakou, N. Kostomitsopoulos, and L. H. Margaritis, "Transient and cumulative memory impairments induced by GSM $1.8 \mathrm{GHz}$ cell phone signal in a mouse model," Electromagnetic Biology and Medicine, vol. 32, no. 1, pp. 95-120, 2013.

[17] T. S. Aldad, G. Gan, X. B. Gao, and H. S. Taylor, "Fetal radiofrequency radiation exposure from $800-1900 \mathrm{MHz}^{-}$ rated cellular telephones affects neurodevelopment and behavior in mice," Scientific Reports, vol. 2, article no. 312, 2012.

[18] Y. Son, Y. J. Jeong, J. H. Kwon, H. D. Choi, J. K. Pack, N. Kim, Y. S. Lee, and H. J. Lee, "1,950 MHz radiofrequency electromagnetic fields do not aggravate memory deficits in 
5xFAD mice," Bioelectromagnetics, vol. 37, no. 6, pp. 391399, 2016.

[19] Z. J. Sienkiewicz, R. P. Blackwell, R. G. Haylock, R. D. Saunders, and B. L. Cobb, "Low-level exposure to pulsed $900 \mathrm{MHz}$ microwave radiation does not cause deficits in the performance of a spatial learning task in mice," Bioelectromagnetics, vol. 21, no. 3, pp. 151-158, 2000.

[20] D. Dubreuil, T. Jay, and J. M. Edeline, "Head-only exposure to GSM $900-\mathrm{MHz}$ electromagnetic fields does not alter rat's memory in spatial and non-spatial tasks," Behavioural Brain Research, vol. 145, no. 1-2, pp. 51-61, 2003.

[21] J. S. Lee, J. Y. Kim, H. J. Kim, J. C. Kim, J. S. Lee, N. Kim, and M. J. Park, "Effects of combined radiofrequency field exposure on amyloid-beta-induced cytotoxicity in HT22 mouse hippocampal neurones," Journal of Radiation Research, vol. 57, no. 6, pp. 620-626, 2016.

[22] J. Jacob, T. Durand, L. Feuvret, J. J. Mazeron, J. Y. Delattre, K. Hoang-Xuan, et al., "Cognitive impairment and morphological changes after radiation therapy in brain tumors: a review," Radiotherapy and Oncology, vol. 128, no. 2, pp. 221-228, 2018.

[23] Y. Son, M. Yang, J. S. Kim, J. Kim, S. H. Kim, J. C. Kim, et al., "Hippocampal dysfunction during the chronic phase following a single exposure to cranial irradiation," Experimental Neurology, vol. 254, pp. 134-144, 2014.

[24] Y. Son, M. Yang, S. Kang, S. Lee, J. Kim, J. Kim, et al., "Cranial irradiation regulates CREB-BDNF signaling and variant $\mathrm{BDNF}$ transcript levels in the mouse hippocampus," Neurobiology of Learning and Memory, vol. 121, pp. 12-19, 2015.

[25] Y. Son, M. Yang, H. Wang, and C. Moon, "Hippocampal dysfunctions caused by cranial irradiation: a review of the experimental evidence," Brain, Behavior, and Immunity, vol. 45, pp. 287-296, 2015.

[26] J. S. Kim, M. Yang, S. H. Kim, T. Shin, and C. Moon, "Neurobiological toxicity of radiation in hippocampal cells," Histology and Histopathology, vol. 28, no. 3, pp. 301310, 2013.

[27] N. K. Sharma, R. Sharma, D. Mathur, S. Sharad, G. Min- has, K. Bhatia, A. Anand, and S. P. Ghosh, "Role of ionizing radiation in neurodegenerative diseases," Frontiers in Aging Neuroscience, vol. 10, article no. 134, 2018.

[28] M. T. Makale, C. R. McDonald, J. A. Hattangadi-Gluth, and S. Kesari, "Mechanisms of radiotherapy-associated cognitive disability in patients with brain tumours," Nature Reviews Neurology, vol. 13, no. 1, pp. 52-64, 2017.

[29] E. S. Jung, H. Hong, C. Kim, and I. Mook-Jung, "Acute ER stress regulates amyloid precursor protein processing through ubiquitin-dependent degradation," Scientific Reports, vol. 5, article no. 8805, 2015.

[30] E. G. Moros, W. L. Straube, and W. F. Pickard, "The radial transmission line as a broad-band shielded exposure system for microwave irradiation of large numbers of culture flasks," Bioelectromagnetics, vol. 20, no. 2, pp. 65-80, 1999.

[31] W. F. Pickard, W. L. Straube, and E. G. Moros, "Experimental and numerical determination of SAR distributions within culture flasks in a dielectric loaded radial transmission line," IEEE Transactions on Biomedical Engineering, vol. 47, no. 2, pp. 202-208, 2000.

[32] K. Y. Lee, B. C. Kim, N. K. Han, Y. S. Lee, T. Kim, J. H. Yun, N. Kim, J. K. Pack, and J. S. Lee, "Effects of combined radiofrequency radiation exposure on the cell cycle and its regulatory proteins," Bioelectromagnetics, vol. 32, no. 3, pp. 169-178, 2011.

[33] H. J. Hong and Y. J. Chong, "Noise measurement and analysis in mobile frequency bands of Korea," in Proceedings of 2016 International Conference on Information and Communication Technology Convergence (ICTC), Jeju, South Korea, 2016, pp. 778-780.

[34] R. A. Stetler, Y. Gao, A. P. Signore, G. Cao, and J. Chen, "HSP27: mechanisms of cellular protection against neuronal injury," Current Molecular Medicine, vol. 9, no. 7, pp. 863-872, 2009.

[35] Y. J. Lee, D. H. Lee, C. K. Cho, H. Y. Chung, S. Bae, G. J. Jhon, J. W. Soh, D. I. Jeoung, S. J. Lee, and Y. S. Lee, "HSP25 inhibits radiation-induced apoptosis through reduction of PKC $\delta$-mediated ROS production," Oncogene, vol. 24, no. 23, pp. 3715-3725, 2005. 
Kyeonghee Yoon

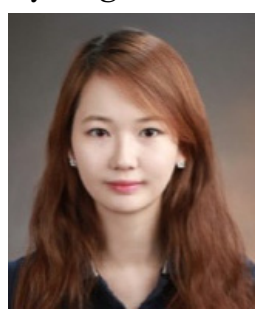

received the B.S. degrees in School of Food Science \& Biotechnology from Kyungpook National University in 2017. And received the M.S defrees in College of Pharmacy from Ewha Woman University in 2020. Her research interests include the effects of RFs on cells.

\section{Sojung Choi}

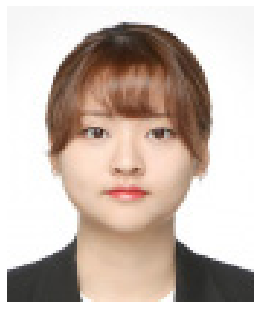

graduated from Department of Life Science and Biotechnology, Soonchunhyang University, Korea, in 2016. She received M.S degree in The Graduate School of Pharmaceutical Science, Ewha Womans University, in 2018. Her research interests are Alzheimer's disease, cell biology, radiation biology and RF-EMF. Since 2020, she has been working as a Associate Researcher for Rznomics. The main research field is retinitis pigmentosa.

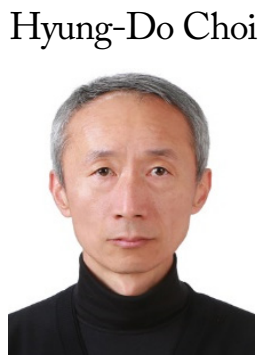

received M.S. and Ph.D. degrees in material sciences from Korea University in 1989 and 1996, respectively. Since 1997, he has been with Electronics and Telecommunications Research Institute, Korea, where he is presently a project leader of Radio \& Satellite Research Division. He has carried out research in field of biological effects of $\mathrm{RF}$ radiation and developed $\mathrm{RF}$ radiation protection standards.

\section{Nam Kim}

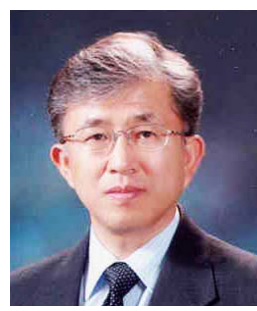

received the B.S., M.S., and Ph.D. degrees in the electronics engineering from Yonsei University, Seoul, Korea, in 1981, 1983, and 1988, respectively. He is a professor in the college of electrical and computer engineering, Chungbuk National University from 1989. His scientific interests are focused on the health effect of the EMF, RF dosimetry and SAR, the reduction and protection technology of the EMF hazards, and the guideline and standards on the EMF.

Sang Bong Jeon

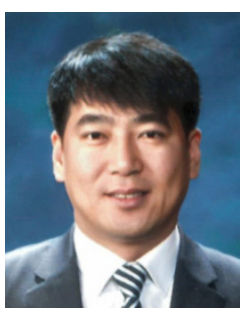

received his B.S., M.S., and Ph.D. degrees in electronic engineering from Yeungnam University, Gyeongsan, Rep. of Korea, in 2001, 2003, and 2007, respectively. From 2008 to 2010, he was a senior research engineer at the Korea Radio Promotion Association, Seoul, Rep. of Korea, where he conducted research in the fields of electromagnetic compatibility technology. Since 2010, he has been with Radio \& Satellite Research Division, Electronics and Telecommunications Research Institute, Daejeon, Rep. of Korea. His research interests include bioelectromagnetics and electromagnetic compatibility.

\section{Kyung-Min Lim}

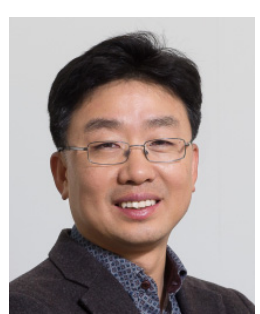

received Ph.D. in Toxicology from Seoul National University, Seoul, Korea in 2009. Since then, he worked as a principal researcher in Drug Discovery Team of AmorePacific R\&D center, Korea. Now, he is an associate professor at Ewha Womans' University. His research topic is toxicology, dermatology and alternative to animal experimentations.

Hae-June Lee

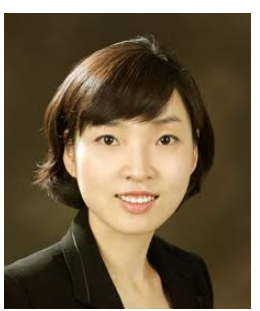

received the B.S., M.S., and Ph.D. degrees from the College of Veterinary Medicine, Chonnam National University, Gwangju, Korea, in 2001, 2003, and 2005 , respectively. She has been working as a principle researcher at the Korea Institute of Radiological \& Medical Sciences since 2005. Her current research interests include the effects of electromagnetic fields on animals.

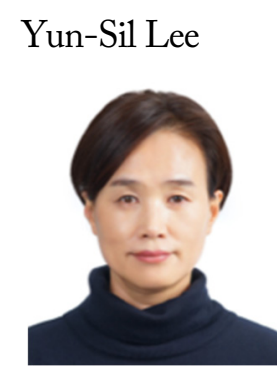

is a full professor of Graduate School of Pharmaceutical Sciences at Ewha Womans University. She received her B.S., M.S. and Ph.D. in College of Pharmacy from Ewha Womans University. She went on to do postdoctoral work in NCI, USA before 18 years working at Korea Institute of Radiological and Medical Sciences as a Principal Scientist, where she had a lot of works about radiation damage and RF-EMF. She has published more than $200 \mathrm{SCI}(\mathrm{E})$ papers and has been invited to an international symposium as an invited speaker. She is also an editor or reviewer of various related fields. 